\title{
Condições de processamento e comercialização de queijo-de-minas frescal
}

\author{
[Conditions of production and distribution of minas fresh cheese] \\ J.S. Rocha, F.C.A. Buriti, S.M.I. Saad* \\ Faculdade de Ciências Farmacêuticas - USP \\ Av. Prof. Lineu Prestes, 580 - Bloco 16 \\ 05508-000 - São Paulo, SP
}

\begin{abstract}
RESUMO
Avaliaram-se a evolução da contaminação microbiana de queijo-de-minas frescal durante sua vida de prateleira e a padronização e qualidade de sete marcas (A a G) de queijo (3 a 4 lotes de cada), adquiridas em supermercados de São Paulo. Os parâmetros determinados incluíram contagens de Staphylococcus spp., coliformes, Escherichia coli e bactérias láticas, pH, umidade e dureza instrumental, após 7, 14 e 21 dias de fabricação dos queijos. Avaliou-se, também, o comportamento da população de coliformes e $E$. coli durante o processamento de queijo-de-minas frescal com leite pasteurizado e cru. As contagens mais elevadas de Staphylococcus spp., coliformes e E. coli detectadas foram, respectivamente, 7,83 (B), 8,02 (B) e 7,83 log UFC/g (C). Todas as marcas, exceto a F, apresentaram índices de contaminação acima do recomendável. Seis das sete marcas apresentaram-se impróprias para o consumo já aos sete dias de fabricação. As populações de coliformes e de E. coli dos queijos preparados no laboratório aumentaram 2,5 ciclos log durante o processamento com leite pasteurizado e 4,5 ciclos log (coliformes) e 5 ciclos log (E. coli) em queijo fabricado com leite cru. Uma reavaliação das condições de fabricação, distribuição, comercialização e prazo de validade de queijo-de-minas frescal é necessária.
\end{abstract}

Palavras-chave: queijo-de-minas frescal, contaminação, microbiologia, inspeção

\begin{abstract}
Microbial contamination of minas fresh cheese during its shelf-life and general aspects of quality and standardization of seven different trademarks (A to G), purchased in grocery stores in São Paulo, were investigated. For this purpose, counts of Staphylococcus spp., coliforms, Escherichia coli, and lactic acid bacteria, besides pH, moisture, and instrumental measurement of hardness were determined 7, 14 and 21 days after cheese production. The variation of coliforms and E. coli counts during the production of cheeses from pasteurized and raw milk was also evaluated. The highest counts of Staphylococcus spp., coliforms and E. coli were, respectively, 7.83 (B), 8.02 (B), and $7.83 \log C F U / g$ (C). Except for trademark $F$, all others presented contamination levels above those recommended by the Brazilian legislation. Cheeses from six out of seven trademarks were already unsuitable for consumption 7 days after production. The counts of total coliforms and $\mathrm{E}$. coli in cheeses prepared in the laboratory increased $2.5 \log$ cycles during their manufacture using pasteurized milk, and 4.5 log cycles (coliforms) and 5 log cycles (E. coli) when prepared with raw milk. Conditions of production, distribution, and expiration date of commercial minas fresh cheese need improvement.
\end{abstract}

Keywords: minas fresh cheese, contamination, microbiology, inspection

Recebido em 19 de fevereiro de 2005

Aceito em 13 de fevereiro de 2006

*Autor para correspondência (corresponding author)

E-mail: susaad@usp.br

Apoio: CAPES/FAPESP (Proc. 00/03803-7, 00/14679-5 e 00/14680-3) 


\section{INTRODUÇÃO}

O queijo-de-minas frescal é um queijo para o consumo imediato e de curta vida de prateleira, devendo ser comercializado logo após a sua fabricação (Furtado, 1999). Apresenta grande susceptibilidade a contaminações microbianas, que podem ocorrer a partir do leite utilizado como matéria-prima, ou por contaminações cruzadas durante ou após o processamento. As contaminações, aliadas às alterações decorrentes podem, em poucos dias, tornar o queijo inaceitável ou até mesmo impróprio para o consumo.

Diversos relatos indicam que queijos do tipo minas frescal comercializados no Brasil são amplamente contaminados. Araújo et al. (1997) observaram que $100 \%$ das amostras de queijode-minas frescal analisadas, obtidas em supermercados e padarias localizadas na cidade do Rio de Janeiro, revelaram a presença de coliformes fecais em níveis acima dos tolerados. Oliveira et al. (1998) relataram a detecção de coliformes totais e fecais acima dos permitidos, respectivamente, em $46,9 \%$ e $9,4 \%$ das amostras de queijo-de-minas elaboradas por seis fábricas de laticínios localizadas na região nordeste do estado de São Paulo. Pereira et al. (1999) observaram, em Belo Horizonte, que 90\% das amostras de queijo-de-minas frescal analisadas no período de 1995-96 apresentaram coliformes fecais acima dos limites estabelecidos por lei.

Relatos sobre a contaminação de queijo-deminas frescal por patógenos, como Listeria monocytogenes, Staphylococcus aureus e Aeromonas, têm sido freqüentes, em várias cidades brasileiras (Sabioni e Maia, 1998; Silva et al., 1998; Almeida Filho e Nader Filho, 2000; Bulhões e Rossi Júnior, 2002).

O trabalho objetivou avaliar a evolução da contaminação microbiana de queijo-de-minas frescal durante sua vida de prateleira e a padronização e qualidade em sete marcas distintas de queijos adquiridas em pequenos, médios e grandes supermercados da cidade de São Paulo, durante um ano.

\section{MATERIAL E MÉTODOS}

Durante o período de 14 meses, de julho de 2001 a setembro de 2002, foram adquiridas sete marcas de queijo-de-minas frescal (marcas A a
G), em um total de quatro lotes das marcas A, C, E, F e G, e de três lotes das marcas B e D. Os queijos foram adquiridos em pequenos, médios e grandes supermercados de São Paulo e, a cada coleta, três a quatro queijos de cada lote, embalados individualmente (embalagens contendo cerca de $400 \mathrm{~g}$ de queijo), eram adquiridos. Os queijos foram armazenados em sua embalagem original a $5^{\circ} \mathrm{C}$, até serem analisados, em duplicata, 7, 14 e 21 dias após a data de fabricação expressa na embalagem.

Decorrido o tempo de armazenamento, porções de $25 \mathrm{~g}$ de queijo (retiradas em condições de assepsia) foram homogeneizadas com $225 \mathrm{ml}$ de água peptonada $0,1 \%$, utilizando-se um Bag Mixer $^{1}$. Diluições decimais subseqüentes foram preparadas, utilizando o mesmo diluente. Alíquotas de $0,1 \mathrm{ml}$ de cada diluição das amostras foram transferidas para placas contendo ágar Baird-Parker (ágar BP; base para ágar BairdParker $^{2}$, adicionado de telurito e gema de ovo suplemento SR054C), para a contagem de Staphylococcus spp. Alíquotas de $1 \mathrm{ml}$ de cada diluição foram transferidas para placas Petrifilm $^{\mathrm{TM}}$ E. coli count plates $^{3}$, para a contagem de coliformes totais e de Escherichia coli, de acordo com as instruções do fabricante. A incubação das placas de ágar BP e de Petrifilm ${ }^{\mathrm{TM}} \mathrm{EC}$ foi realizada a $35^{\circ}-37^{\circ} \mathrm{C}$ por $48 \mathrm{e}$ por 24 horas, respectivamente (Compendium... 1992; Standard... 1992). Para a contagem de bactérias láticas, alíquotas de $0,1 \mathrm{ml}$ de cada diluição foram transferidas para placas contendo ágar DeMan-Rogosa-Sharpe ${ }^{4}$ e incubadas a $30^{\circ} \mathrm{C}$ por 48 horas (Compendium... 1992; Standard... 1992).

As determinações de $\mathrm{pH}$ dos queijos foram realizadas em medidor de $\mathrm{pH}$-Analyser Modelo $300 \mathrm{M}^{5}$, empregando-se um eletrodo tipo penetração modelo $\mathrm{DME}-\mathrm{CF}^{6}$. A umidade foi determinada a $70^{\circ} \mathrm{C}$, em estufa a vácuo modelo MA030/12 ${ }^{7}$, a partir de amostras de $5 \mathrm{~g}$. A dureza instrumental dos queijos foi determinada por teste de dupla compressão de amostras cilíndricas $(2,0 \mathrm{~cm}$ de diâmetro e $3,0 \mathrm{~cm}$ de

\footnotetext{
${ }^{1}$ Interscience, St. Nom, França.

${ }^{2}$ Oxoid Ltd., Basingstoke, Reino Unido.

${ }^{3}$ Petrifilm ${ }^{\mathrm{TM}}$ EC; 3M Microbiology, St. Paul, MN, EUA.

${ }^{4}$ Ágar MRS; Oxoid.

${ }^{5}$ Analyser Comércio e Indústria Ltda., São Paulo, Brasil.

${ }^{6}$ Digimed, São Paulo, Brasil.

${ }^{7}$ Marconi, Piracicaba, Brasil.
} 
altura), em texturômetro $\mathrm{TA}-\mathrm{XT} 2^{8}$, utilizando placa de alumínio retangular de $10 \times 9 \mathrm{~cm}^{2}$. A taxa de compressão empregada foi de $20 \%$ de deformação, em relação à altura inicial da amostra e a velocidade foi de $2 \mathrm{~mm} \mathrm{~s}^{-1}$. As amostras cilíndricas foram mantidas à temperatura ambiente (cerca de $25^{\circ} \mathrm{C}$ ) por 20 minutos antes de serem submetidas ao teste. Os dados foram coletados usando-se do programa ${ }^{8}$ Texture Expert for Windows - versão 1.20.

Com a finalidade de verificar o comportamento da população de coliformes totais e de E. coli durante $\mathrm{o}$ processamento do queijo, foram produzidos oito lotes do queijo no próprio laboratório, quatro deles a partir de leite tipo B pasteurizado comercial e quatro a partir de leite cru, proveniente de regiões próximas à cidade de São Paulo, e colhido por ordenha manual na manhã do experimento, resfriado e transportado para o laboratório em caixas térmicas. Para a fabricação de todos os queijos, o leite foi aquecido a $36-38^{\circ} \mathrm{C}$ e, em seguida, adicionado de cultura lática mesofílica homofermentativa do tipo O, liofilizada comercial, composta de Lactococcus lactis subsp. lactis e Lactococcus lactis subsp. cremoris ${ }^{9}$. A cultura, adicionada na proporção de $10 \mathrm{mg} / \mathrm{l}$ de leite, era do tipo DVS (direct vat set), para adição direta ao leite. O coagulante comercial Estrela (Christian Hansen; $85 \%$ de pepsina bovina e $15 \%$ quimosina bovina) foi adicionado, na proporção recomendada pelo fabricante, quando o leite atingiu $20-22^{\circ}$ Dornic. Houve adição complementar de cloreto de cálcio $(0,25 \mathrm{~g} / 1$ de leite). Após agitação, o leite adicionado dos ingredientes foi mantido a $36^{\circ} \mathrm{C}$, em repouso, até coagulação completa, quando, então, procedeu-se o corte de coalhada e, posteriormente, repouso, agitação, dessoragem, drenagem do soro e enformagem. Após sucessivas viragens, de modo a obter uma dessoragem completa, procedeu-se a salga dos queijos em superfície (1g sal/100g queijo). Os queijos foram, então, mantidos em refrigeração por 6 horas adicionais, quando foram embalados em sacos de polietileno. Posteriormente, os queijos foram armazenados em refrigeração $\left(8,5^{\circ} \mathrm{C}\right)$ durante aproximadamente 18 horas, obtendo-se, assim, o produto final.

\footnotetext{
${ }^{8}$ Stable Micro Systems, Haslemere, Inglaterra.

${ }^{9}$ Christian Hansen (R-704), Valinhos, Brasil.
}

As contagens de coliformes e de E. coli foram realizadas no leite, utilizado como principal matéria-prima para a produção dos diversos tipos de queijo-de-minas frescal (leite tipo B pasteurizado e leite cru), durante $\mathrm{o}$ processamento do queijo - entre a etapa de dessoragem e a de enformagem do queijo - e no produto final. Os procedimentos seguidos para a realização das contagens microbianas de coliformes e de E. coli foram os mesmos empregados para os queijos comerciais e descritos anteriormente.

O delineamento experimental foi inteiramente ao acaso, baseado na disponibilidade das marcas estudadas nos diferentes pontos de venda selecionados, em cada dia em que foram efetuadas as amostragens, e nas datas de fabricação dos diferentes produtos disponíveis em cada ponto de venda. Preferencialmente, eram selecionadas as marcas com data de fabricação mais recente, de modo a possibilitar análises ao longo de todo o período de armazenamento proposto, ou seja, de 7 a 21 dias após a data de fabricação descrita na embalagem. A seleção das marcas estudadas teve como base a maior disponibilidade para a aquisição nos diferentes pontos de venda. Todas as marcas selecionadas apresentavam inspeção federal. Utilizou-se um esquema fatorial $7 \times 3$, constituído de sete marcas de queijo-de-minas frescal disponíveis no varejo e três tempos $(7,14$ e 21 dias após a data de fabricação descrita na embalagem), com três a quatro repetições, ou seja, três a quatro diferentes lotes de cada marca, adquiridos em períodos distintos (Barros Neto et al., 2003).

\section{RESULTADOS E DISCUSSÃO}

Verificou-se que os queijos eram comercializados com datas de fabricação freqüentemente superiores a sete ou mesmo a 10 dias, particularmente em estabelecimentos comerciais maiores, o que impossibilitou a coleta com um período de fabricação inferior a sete dias. Do total de marcas comerciais avaliadas, apenas alguns lotes das marcas B, C e E (17,4\% de todas as amostras) foram encontrados no mercado com 4 dias ou menos de fabricação. Assim, foram detectadas falhas na própria distribuição do queijo-de-minas frescal para os pontos de venda da cidade de São Paulo, 
particularmente nos supermercados de grandes redes. Nesses supermercados, observou-se que, além do produto chegar com data de fabricação avançada, eram adquiridos grandes estoques, o que impossibilitava uma reposição freqüente.

A Tab. 1 indica os ingredientes presentes nos queijos das sete marcas comerciais avaliadas, o tipo de inspeção e a origem dos queijos, de acordo com o que foi expresso em suas embalagens. Entretanto, é importante salientar que, apesar de algumas marcas não descreverem a adição de determinados ingredientes em suas embalagens, esse fato não significa que tal adição não foi realizada. Para a marca $\mathrm{D}$, a rotulagem indicou que a cultura lática (fermento lático) foi totalmente substituída pela acidificação direta com ácido lático, prática esta que encontra amparo na legislação brasileira (Brasil, 1997a).

Tabela 1. Tabela indicativa dos ingredientes presentes nas sete diferentes marcas comerciais de queijo-deminas frescal avaliadas, tipo de inspeção e origem, expressos nas embalagens

\begin{tabular}{lcccccccccc}
\hline Marca & Leite & $\begin{array}{c}\text { Leite } \\
\text { pasteurizado }\end{array}$ & $\begin{array}{c}\text { Fermento } \\
\text { lático }\end{array}$ & $\begin{array}{c}\text { Ácido } \\
\text { lático }\end{array}$ & Acidulante & Coalho & $\begin{array}{c}\text { Cloreto } \\
\text { de cálcio }\end{array}$ & Sal & $\begin{array}{c}\text { Tipo de } \\
\text { inspeção }\end{array}$ & $\begin{array}{c}\text { Estado de } \\
\text { origem }\end{array}$ \\
\hline $\mathrm{A}$ & $\mathrm{X}$ & & $\mathrm{X}$ & & & $\mathrm{X}$ & & $\mathrm{X}$ & Federal & $\mathrm{SP}$ \\
$\mathrm{B}$ & & $\mathrm{X}$ & $\mathrm{X}$ & & $\mathrm{X}$ & & $\mathrm{X}$ & Federal & SP \\
$\mathrm{C}$ & & $\mathrm{X}$ & $\mathrm{X}$ & & & $\mathrm{X}$ & $\mathrm{X}$ & $\mathrm{X}$ & Federal & MG \\
$\mathrm{D}$ & & $\mathrm{X}$ & & $\mathrm{X}$ & & $\mathrm{X}$ & $\mathrm{X}$ & $\mathrm{X}$ & Federal & MG \\
$\mathrm{E}$ & $\mathrm{X}$ & & $\mathrm{X}$ & & $\mathrm{X}$ & $\mathrm{X}$ & $\mathrm{X}$ & & Federal & MG \\
$\mathrm{F}$ & & $\mathrm{X}$ & $\mathrm{X}$ & & & $\mathrm{X}$ & & $\mathrm{X}$ & Federal & SP \\
$\mathrm{G}$ & $\mathrm{X}$ & & $\mathrm{X}$ & & & $\mathrm{X}$ & $\mathrm{X}$ & $\mathrm{X}$ & Federal & SP \\
\hline $\mathrm{X}$ & & & & & & & & & &
\end{tabular}

$\mathrm{X}=$ presença do ingrediente.

Na Fig.1, mostra-se a evolução da população média (e respectivos desvios-padrão) de coliformes totais, de E. coli e de Staphylococcus spp., para as sete marcas comerciais de queijode-minas frescal avaliadas, ao longo do período de armazenamento estudado. Todas as marcas avaliadas, exceto a $\mathrm{F}$, apresentaram índices de contaminação acima do recomendável. As contagens mais elevadas de Staphylococcus spp., de coliformes e de $E$. coli detectadas foram de 7,83 (B), de 8,02 (B) e de 7,83log UFC/g (C), respectivamente. Todas as marcas de queijos analisadas apresentavam inspeção federal (Tab. 1). Dos lotes avaliados nos diferentes períodos de amostragem estudados, $61 \%$ apresentaram contagens de E. coli acima de 3,7log UFC/g (ou $5 \times 10^{3} \mathrm{UFC} / \mathrm{g}$ ), limite este estabelecido para coliformes a $45^{\circ} \mathrm{C}$ em queijos de muito alta umidade (acima de 55\%), o que inclui o queijode-minas frescal (Brasil, 2001). Dentre as marcas analisadas, somente a $\mathrm{F}$ estava de acordo com a Resolução 12/2001 que estabelece os requisitos microbiológicos do queijo-de-minas frescal (Brasil, 2001). A baixa contaminação dessa marca foi acompanhada de contagem de bactérias láticas drasticamente inferior em relação à média das demais $(3,6 \log \mathrm{UFC} / \mathrm{g})$, apesar dos valores médios de $\mathrm{pH}$ mais elevados (próximos a 6), quando comparados aos das demais marcas (Fig. 1 e 2). A possibilidade da adição de conservante a esse queijo, não especificado no rótulo, não pode ser descartada.

As marcas com os menores índices de contaminação ( $F$ e $G$ ), apresentaram valores de $\mathrm{pH}$ mais elevados e dureza instrumental mais estável. Esse fato indica que uma menor contaminação inicial do produto resulta em uma melhor estabilidade durante o seu armazenamento e, conseqüentemente, em uma vida de prateleira mais extensa, embora inferior àquela descrita nas embalagens atualmente. Os menores índices de contaminação das marcas $\mathrm{F}$ e $\mathrm{G}$ aliados às menores populações de bactérias láticas reforçam a possibilidade de adição de conservante a esses queijos, não explicitada na embalagem. Embora o fermento lático não tenha sido utilizado na fabricação dos queijos da marca $\mathrm{D}$, populações de bactérias láticas foram encontradas durante todo o armazenamento desse queijo (Fig. 1). Esse fato ocorre normalmente, já que a pasteurização do leite utilizado como matéria prima não visa à eliminação dessas bactérias e sim de microrganismos patogênicos (Smith e Hui, 2004). 

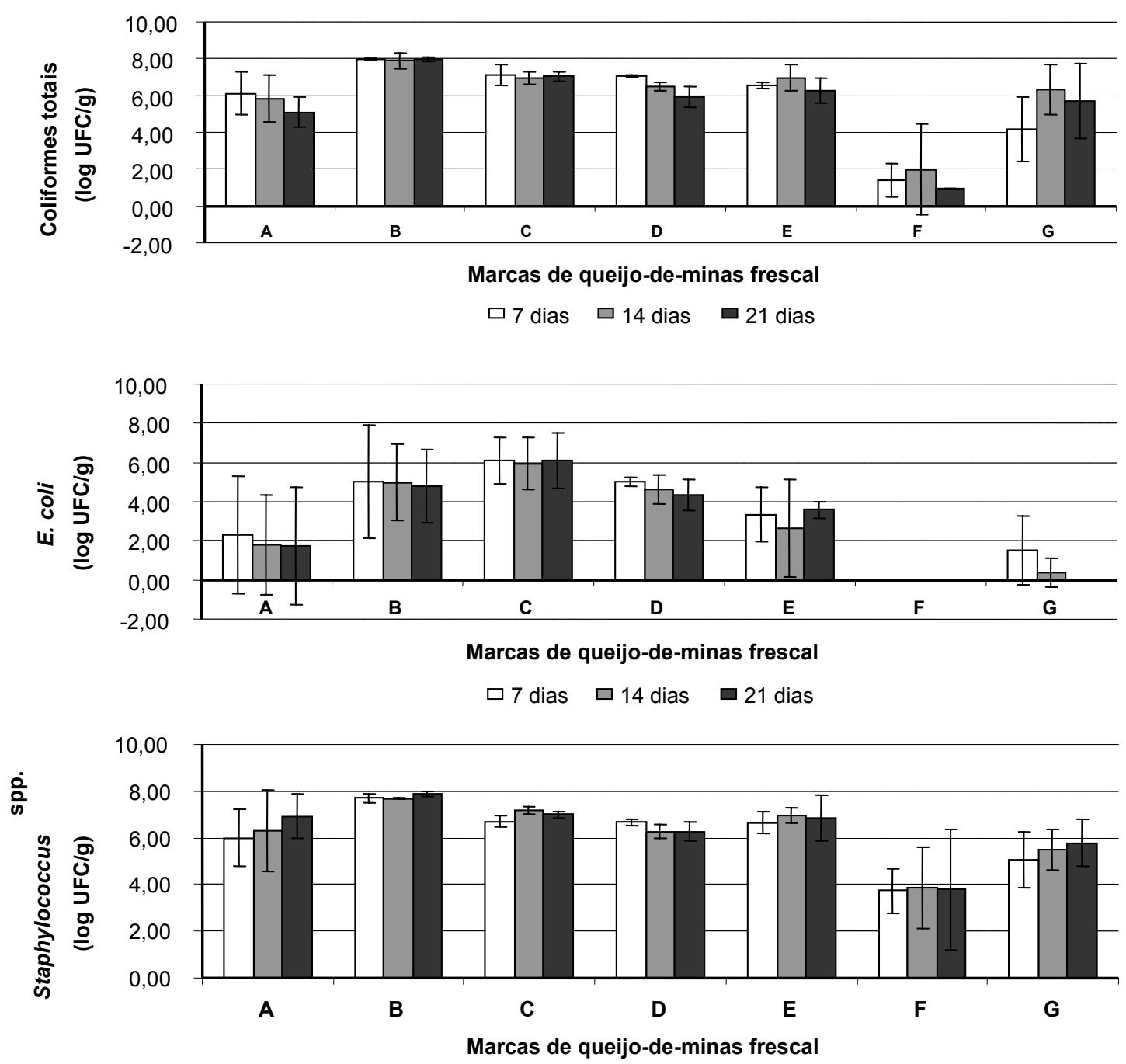

$\square 7$ dias $\square 14$ dias $\square 21$ dias

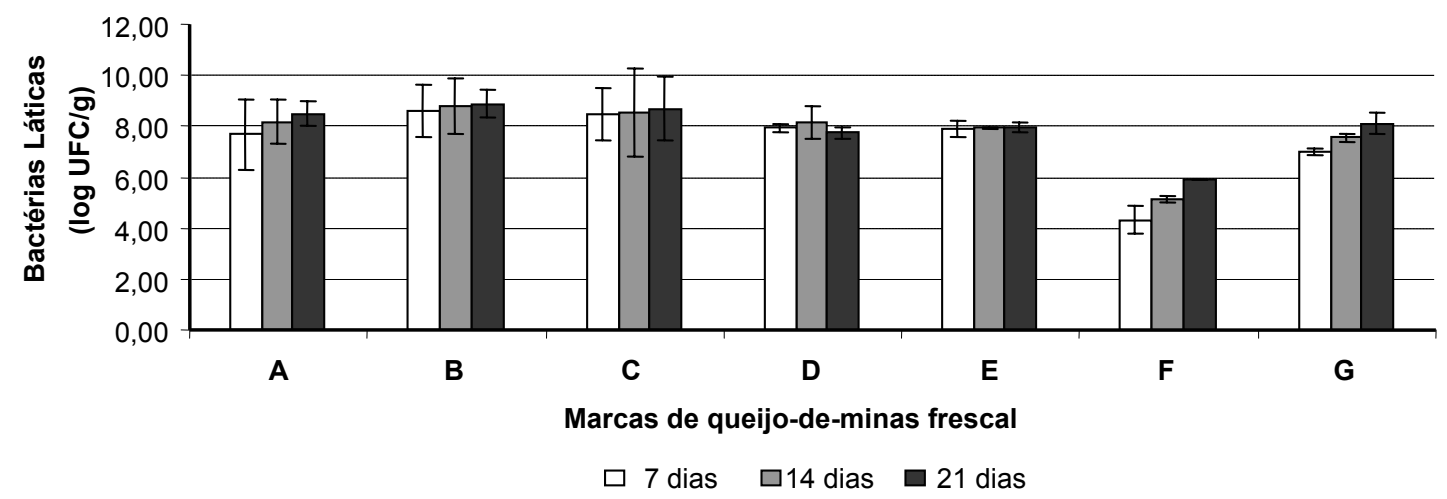

Figura 1. Populações médias de coliformes totais, de Escherichia coli, de Staphylococcus spp. e de bactérias láticas $(\log \mathrm{UFC} / \mathrm{g})$ detectadas nas amostras de sete diferentes marcas comerciais de queijo-de-minas frescal avaliadas aos 7 , 14 e 21 dias após a data de fabricação expressa na embalagem.

* Médias e desvios-padrão de quatro amostragens de cada marca de queijo avaliada. 


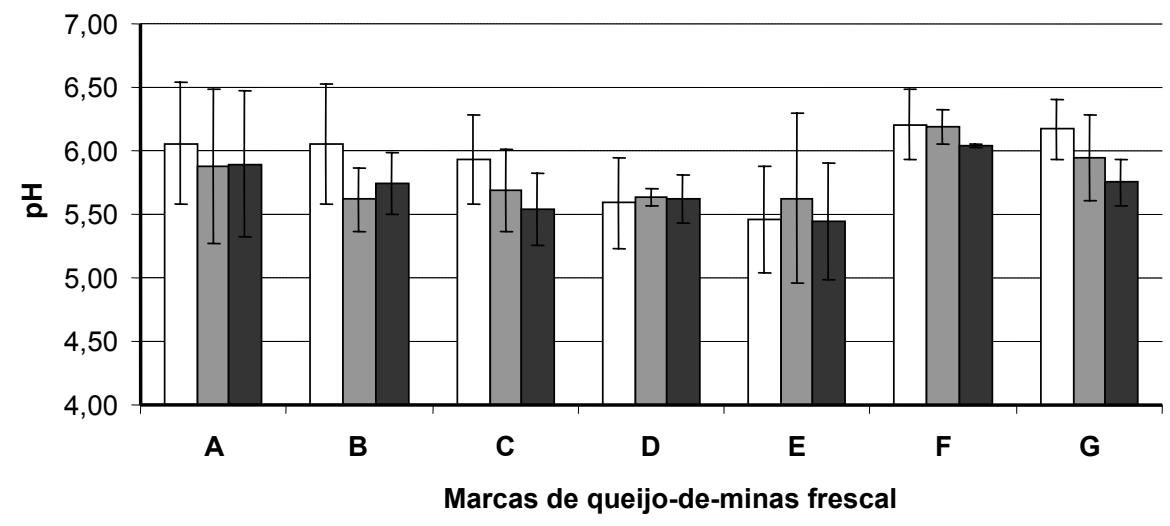

$\square 7$ dias $\square 14$ dias $\square 21$ dias

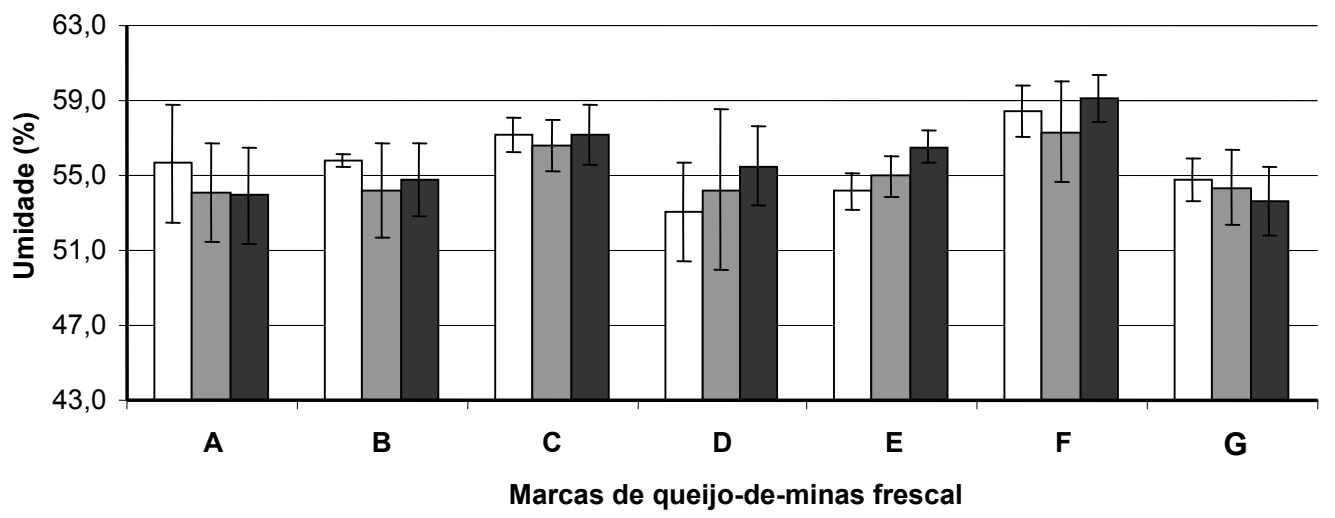

$\square 7$ dias $\square 14$ dias $\square 21$ dias

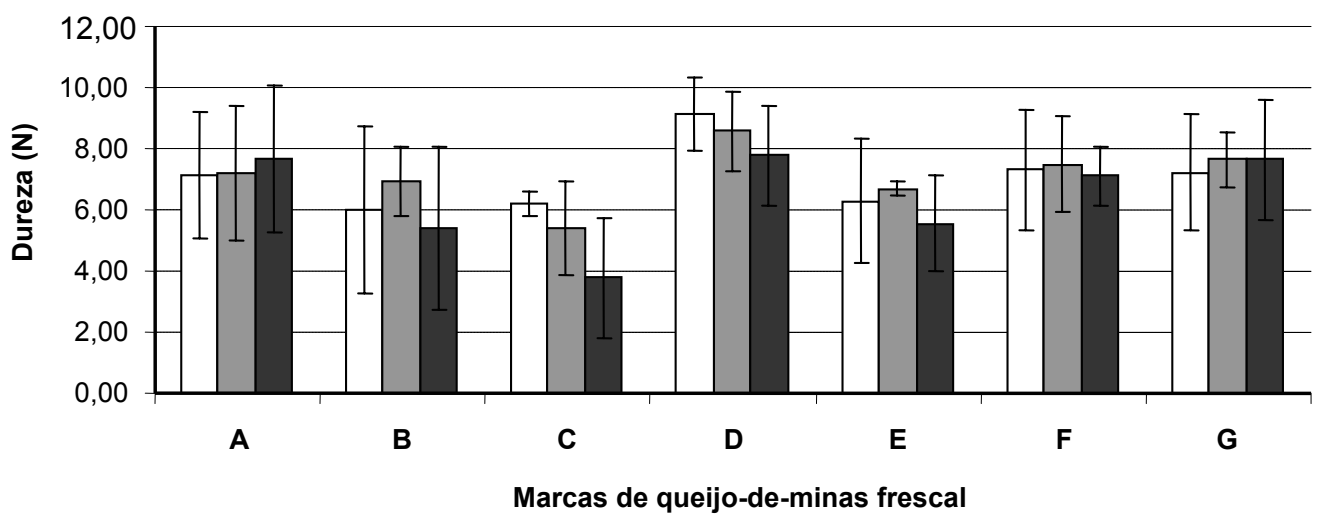

$\square 7$ dias $\square 14$ dias $\square 21$ dias

Figura 2. Valores médios de $\mathrm{pH}$, de umidade e de dureza instrumental (log UFC/g) das amostras de sete diferentes marcas comerciais de queijo-de-minas frescal avaliadas aos 7, 14 e 21 dias após a data de fabricação expressa na embalagem.

${ }^{*}$ Médias e desvios-padrão de quatro amostragens de cada marca de queijo avaliada. 
Apesar dos parâmetros microbiológicos terem permanecido relativamente constantes ao longo da vida de prateleira, verificou-se que seis das sete marcas avaliadas apresentaram-se impróprias para o consumo já aos sete dias de fabricação. Paralelamente, os elevados valores de desvio-padrão obtidos para os diferentes parâmetros microbiológicos analisados indicaram grande heterogeneidade entre os lotes de um mesmo fabricante (Fig. 1). Essa heterogeneidade também foi observada para $\mathrm{pH}$, umidade e dureza instrumental das amostras (Fig. 2). Deve ser ressaltado que os diferentes queijos de cada fabricante foram adquiridos em meses distintos do ano, o que influencia as características físico-químicas e, principalmente, microbiológicas dos produtos. Apesar disto, a excessiva heterogeneidade e os altos índices de contaminação detectados evidenciam a necessidade de implantação de programas mais rigorosos de garantia de qualidade nas indústrias de laticínios, de modo a padronizar o produto.

Apesar de não ter sido observado aumento das populações de microrganismos indicadores durante o armazenamento dos queijos, as elevadas populações iniciais desses microrganismos evidenciam o perigo em potencial à saúde do consumidor, principalmente devido à possibilidade de produção de toxinas. $\mathrm{O}$ prazo de validade do queijo-de-minas frescal comercializado chega a 30 dias na maioria dos produtos do varejo (era de 15 dias até 1998), agravando ainda mais a situação. Embora seja considerado um queijo fresco, o queijo-de-minas frescal dificilmente é encontrado nos pontos de venda logo após a sua fabricação. A data de validade estimada pelos fabricantes varia de 21 a 30 dias. No entanto, verificou-se no presente trabalho que as amostras encontravam-se impróprias para o consumo já a partir do sétimo dia. Além disso, os queijos estudados mostravam-se visivelmente deteriorados já aos 21 dias de fabricação e, portanto, não foram analisados em períodos posteriores, mesmo quando prazos de validade mais extensos eram indicados na embalagem.
Na Fig. 3 mostra-se a evolução das populações de coliformes e de E. coli ao longo do processamento dos queijos no laboratório, utilizando leite B pasteurizado comercial e leite cru. A população de coliformes e de E. coli dos queijos preparados no laboratório aumentou de 1 a 4 e de 0 a 3 ciclos log, respectivamente, durante o processamento de queijo com leite pasteurizado (2,5 ciclos log, em média). O aumento dessas populações em queijo fabricado com leite cru foi de 2 a $5(4,5$, em média) e de 4 a 6 (5, em média) ciclos log, respectivamente. Tal aumento indica que bactérias potencialmente patogênicas podem multiplicar-se a níveis perigosos durante o processamento de queijo. Esses dados também reforçam a importância da utilização de leite cru de boa procedência, pasteurização eficiente e processamento adequado para a elaboração de queijos, particularmente de queijo-de-minas frescal, uma vez que, além da contagem de coliformes e, principalmente de $E$. coli, apresentar-se visivelmente mais elevada no leite cru, o aumento nas contagens desses microrganismos revelou ser muito maior durante o processamento de queijo.

A legislação brasileira para laticínios com selo do Serviço de Inspeção Federal (SIF) exige que programas de boas práticas de fabricação (BPF) e de análise de perigos e pontos críticos de controle (APPCC) sejam implantados nas fábricas com o apoio de pessoal especializado e revistos periodicamente (Brasil, 1997b, c; Brasil, 1998). Silva et al. (2003) também apontaram para a necessidade de implantação de APPCC em todos os laticínios e salientaram para a possibilidade de contaminação pósprocessamento. Os autores determinaram pontos críticos de controle associados ao queijo-deminas frescal e detectaram a presença de Listeria spp. na linha de processamento. Assumpção et al. (2003) estudaram um laticínio de processamento de queijo-prato, quanto à contaminação por Staphylococcus aureus e Staphylococcus produtores de coagulase e associaram a alta contaminação do queijo à elevada contagem do patógeno nas mãos e nos antebraços dos manipuladores. 


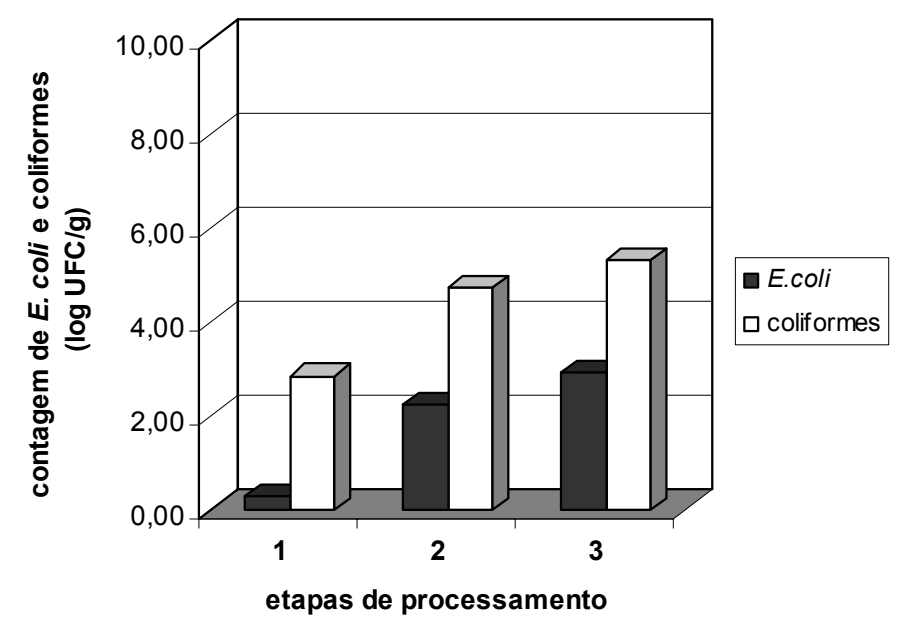

1 = matéria-prima (leite B pasteurizado)

$\mathbf{2}=$ produto em processamento (entre as etapas de dessoragem e enformagem)

$\mathbf{3}=$ produto final (queijo processado)

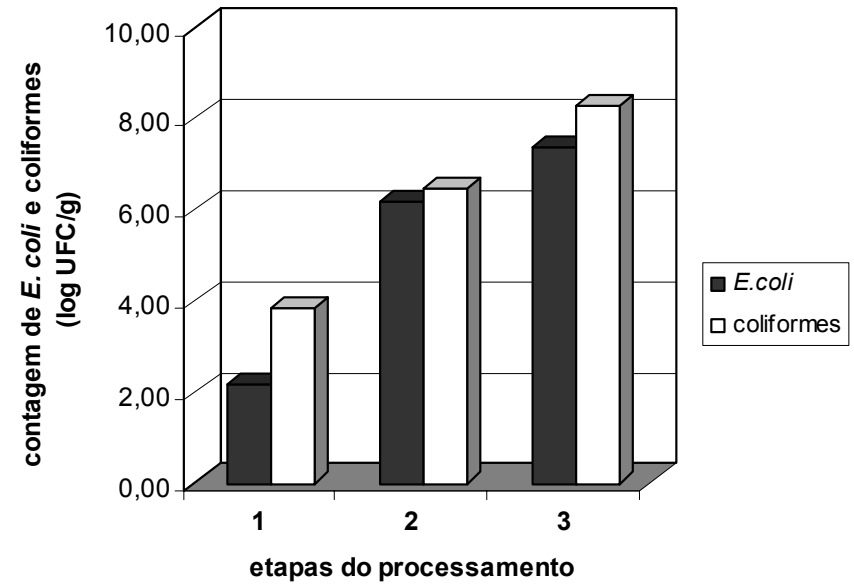

1 = matéria-prima (leite cru)

$\mathbf{2}=$ produto em processamento (entre as etapas de dessoragem e enformagem)

$\mathbf{3}=$ produto final (queijo processado)

Figura 3. Populações médias de Escherichia coli e de coliformes totais em diferentes etapas de processamento de queijo-de-minas frescal elaborado com leite B pasteurizado e leite cru.

Alterkruse et al. (1998) relataram que, de 32 surtos associados ao consumo de queijos nos Estados Unidos de 1973 a 1992, 11 foram atribuídos a falhas no processamento e causaram $75 \%$ do total de 1.700 casos relatados de doenças, $96 \%$ do total de 170 internações hospitalares e os 58 óbitos ocorridos. Segundo os autores, as principais falhas encontradas foram o processamento do queijo utilizando leite cru ou inadequadamente pasteurizado e a contaminação pós-pasteurização. Desses 11 surtos resultantes de falhas no processamento, três foram atribuídos a Salmonella spp., três a Brucella melintensis e os demais a E. coli $\mathrm{O} 27: \mathrm{H} 20$, Listeria monocytogenes, Streptococcus spp. e Staphylococcus aureus (um surto atribuído a cada patógeno), e o surto restante foi de etiologia desconhecida. Garcia-Fulgueiras et al. (2001) 
relataram um surto por Shigella sonnei, veiculado por queijo fresco de leite pasteurizado, ocorrido na Espanha de novembro de 1995 a fevereiro de 1996, com mais de 200 doentes. Os autores atribuíram a ocorrência e a continuidade do surto, respectivamente, à manipulação direta com as mãos, em diferentes etapas de processamento, por manipulador doente, e ao contato do queijo com as superfícies dos equipamentos ou utensílios após o afastamento desse manipulador até que uma limpeza satisfatória fosse conduzida.

Aliado à possibilidade de contaminação da matéria-prima, das superfícies em contato direto ou indireto com o produto durante $\mathrm{o}$ processamento e ao fato da grande multiplicação microbiana ser inevitável durante esse período, a sobrevivência desses contaminantes durante todo o período de processamento (incluindo o período de maturação, no caso de queijos maturados) e de armazenamento deve ser considerada. Assim como foi observado neste trabalho com relação à multiplicação e a sobrevivência dos microrganismos indicadores, bactérias patogênicas como Staphylococcus aureus, Salmonella spp., Listeria spp. e E. coli O157:H7 revelaram capacidade de sobreviver ao processamento de alguns tipos de queijo (Borges et al., 1990; Vieira et al., 1993), incluindo o minas frescal (Saad et al., 2001). A elevada população de microrganismos já no início da vida de prateleira de um queijo, aumenta as chances de ocorrência de surtos e casos isolados de toxinfecção alimentar, ao longo de todo o período de validade do produto. Essas chances são maximizadas por abusos de temperaturas durante o transporte e a distribuição do produto e por uma data de validade extensa, no caso particular de um queijo "fresco", como o queijode-minas frescal.

De fato, alguns surtos resultantes do consumo de queijo-de-minas frescal têm sido descritos. Cerqueira et al. (1994) relataram a ocorrência de um surto, possivelmente por Salmonella spp. e por toxina estafilocócica, ocasionado pelo consumo de queijo-de-minas frescal, no município de Pará de Minas, Minas Gerais. Carmo et al. (2002) relataram um surto ocorrido em Manhuaçu, também em Minas Gerais, envolvendo 50 indivíduos que consumiram queijo-de-minas frescal caseiro contaminado com Staphylococcus aureus produtores de toxina, detectados a uma concentração de $10^{5}$ a $10^{8} \mathrm{UFC} / \mathrm{g}$.

O trabalho evidenciou a falta de padronização do queijo-de-minas frescal, no que se refere aos parâmetros microbiológicos, físico-químicos e de dureza instrumental. A padronização poderia ser melhorada por meio de fiscalização. Uma conscientização dos fabricantes, no sentido de uma maior preocupação para com o consumidor e com a seleção rigorosa do leite, quanto à sua proveniência e à sua pasteurização, bem como com o próprio processamento do queijo seria de suma importância. Assim, uma reavaliação das condições de fabricação, distribuição, comercialização e prazo de validade de queijode-minas frescal é necessária e urgente.

\section{AGRADECIMENTOS}

À Haíssa Roberta Cardarelli, pelas valiosas sugestões durante a elaboração do trabalho preliminar, apresentado, em 2003, no XXII Congresso Brasileiro de Microbiologia.

\section{REFERÊNCIAS BIBLIOGRÁFICAS}

ALMEIDA FILHO, E.S.; NADER FILHO, A. Ocorrência de Staphylococcus aureus em queijo tipo “frescal”. Rev. Saúde Publ., v.6, p.578-580, 2000.

ALTERKRUSE, S.F.; TIMBO, B.B.; MOWBRAY, J.C. et al. Cheese-associated outbreaks of human illness in the United States, 1973 to 1992: sanitary manufacturing practices protect consumers. J. Food Prot., v.61, p.1405-1407, 1998.

ARAÚJO, V.S.; SANTOS, E.C.S.; QUEIROZ, M.L.P. et al. Análise bacteriológica do queijo-de-minas frescal comercializado na cidade do Rio de Janeiro. In: CONGRESSO BRASILEIRO DE MICROBIOLOGIA, 19., Rio de Janeiro, 1997. Anais... Rio de Janeiro: SBM, 1997, p. 283. (Resumo).

ASSUMPÇÃO, E.G.; PICCOLI-VALLE, R.H.; HIRSCH, D. et al. Fontes de contaminação por Staphylococcus aureus na linha de processamento de queijo prato. Arq. Bras. Med. Vet. Zootec., v.55, p.366-370, 2003.

BARROS NETO, B.; SCARMINIO, I.S.; BRUNS, R.E. Como fazer experimentos: pesquisa e desenvolvimento na ciência e na indústria. Campinas: UNICAMP, 2003. 401p.

BORGES, M.F.; BRANDÃO, S.C.C.; PINHEIRO, A.J.R. Sobrevivência de Salmonella spp em queijo-de- 
minas padronizado durante a maturação. Rev. Microbiol., v.21, p.276-281, 1990.

BRASIL. Portaria no 326, de 30 de julho de 1997b, do Ministério da Saúde. Aprova o Regulamento Técnico sobre as Condições Higiênico-Sanitárias e de Boas Práticas de Fabricação para Estabelecimentos Produtores/Industrializadores de Alimentos. Diário Oficial da União, Brasília, 1 ago. 1997. Seção 1, p.16560-16563.

BRASIL. Portaria $n^{-}$352, de 4 de setembro de 1997a. O Ministério de Estado da Agricultura e do Abastecimento institui o regulamento técnico para fixação de identidade e qualidade do queijo-de-minas frescal. In: SANTOS, J.A. (ed). Nova legislação de produtos lácteos e de alimentos para fins especiais, diet, light e enriquecidos. São Paulo: Fonte, 1998. p.76-78.

BRASIL. Portaria $\mathrm{n}^{\mathrm{o}}$ 368, de 4 de setembro de 1997c, do Ministério de Estado da Agricultura e do Abastecimento. Aprova o Regulamento Técnico sobre as Condições Higiênico-Sanitárias e de Boas Práticas de Fabricação para Estabelecimentos Elaboradores/Industrializadores de Alimentos. Diário Oficial da União, Brasília, 8 set. 1997. Seção 1, p.29697-29699.

BRASIL. Portaria $\mathrm{n}^{\mathrm{o}}$ 46, de 10 de fevereiro de 1998. O Ministro de Estado da Agricultura, Pecuária e Abastecimento institui o sistema de análise de perigos e pontos críticos de controle - APPCC. In: NOVA legislação comentada de produtos lácteos. São Paulo: Revista Indústria de Laticínios, 2002. p.267-283.

BRASIL. Resolução RDC $\mathrm{n}^{\mathbf{0}} 12$ de 2 de janeiro de 2001 [on-line]. Disponível em: <http://elegis.bvs.br/leisref/public/showAct.php?id=144\&word $=>$. Acessado em 13 set. 2005 .

BULHÕES, C.C.C.; ROSSI JÚNIOR, O.D. Ocorrência de bactérias do gênero Aeromonas em queijo-de-minas frescal artesanal. Arq. Bras. Med. Vet. Zootec., v.54, p.320-324, 2002.

CARMO, L.S.; DIAS, R.S.; LINARDI, V.R. et al. Food poisoning due to enterotoxigenic strains of Staphylococcus aureus present in Minas cheese and raw milk in Brazil. Food Microbiol., v.19, p.9-14, 2002.

CERQUEIRA, M.M.O.P.; SOUZA, M.R.; FONSECA, L.M. et al. Surto epidêmico de toxinfecção alimentar envolvendo queijo tipo Minas frescal em Pará de Minas. Arq. Bras. Med. Vet. Zootec., v.46, p.723-728, 1994.
COMPENDIUM of methods for the microbiological examination of foods. 3.ed. Washington: American Public Health Association, 1992. 1219p.

FURTADO, M.M. Principais problemas dos queijos: causas e prevenção. São Paulo: Fonte, 1999. 176p.

GARCIA-FULGUEIRAS, A.; SÁNCHEZ, S.; GUILLÉN, J.J. et al. A large outbreak of Shigella sonnei gastroentertis associated with consumption of fresh pasteurised milk cheese. Eur. J. Epidemiol., v.17, p.533-538, 2001.

OLIVEIRA, C.A.F.; MORENO, J.F.G. MESTIERI, L. et al. Características físico-químicas e microbiológicas de queijos minas frescal e mussarela, produzidos em algumas fábricas de laticínios do Estado de São Paulo. Hig. Aliment., v.12, p.31-35, 1998.

PEREIRA, M.L.; GASTELOIS, M.C.A; BASTOS, E.M.A.F. et al. Enumeração de coliformes fecais e presença de Salmonella sp. em queijo-de-minas. Arq. Bras. Med. Vet. Zootec., v.51, p.427-431, 1999.

SAAD, S.M.I.; VANZIN, C.; OLIVEIRA, M.N. et al. Influence of lactic acid bacteria on survival of Escherichia coli $\mathrm{O} 157: \mathrm{H} 7$ in inoculated Minas cheese during storage at $8.5^{\circ} \mathrm{C} . \mathrm{J}$. Food Prot., v.64, p.11511155,2001

SABIONI, J.G.; MAIA, A.R.P. Correlação entre a população de Staphylococcus aureus e a atividade de termonuclease, em queijos Minas-frescal. Hig. Aliment., v.12, p.48-50, 1998.

SILVA, I.M.M.; ALMEIDA, R.C.C.; ALVES, M.A.O. et al. Occurrence of Listeria spp. in critical control points and the environment of Minas Fresh cheese processing. Int. J. Food Microbiol., v.81, p.241-248, 2003.

SILVA, M.C.D.; HOFFER, E.; TIBANA, A. Incidence of Listeria monocytogenes in cheese produced in Rio de Janeiro, Brazil. J. Food Prot., v.61, p.354-356, 1998.

SMITH, J.S.; HUI, Y.H. Food processing. Principles and applications. 1.ed. Oxford: Blackwell, 2004. 511p.

STANDARD methods for the examination of dairy products. 16.ed. Washington: American Public Health Association, 1992. 546p.

VIEIRA, A.B.; VIEIRA, J.M.S.; RAIMUNDO, S.M.C. et al. Comportamento de Listeria monocytogenes em queijo-de-minas frescal. In: CONGRESSO BRASILEIRO DE MICROBIOLOGIA, 17., Santos, 1993. Anais... São Paulo: SBM, 1993. p.4. (Resumo). 